Original Research Paper

\title{
Biochar Types from Latrine Waste and Sewage Sludge Differ in Physico-Chemical Properties and Cadmium Adsorption
}

\author{
Koetlisi Andreas Koetlisi and Pardon Muchaonyerwa \\ School of Agricultural, Earth and Environmental Sciences, \\ University of KwaZulu-Natal, Private Bag X01 Scottsville 3209, South Africa
}

\author{
Article history \\ Received: 17-07-2017 \\ Revised: $30-08-2017$ \\ Accepted: 23-11-2017 \\ Corresponding Author: \\ Koetlisi Andreas Koetlisi \\ School of Agricultural, Earth \\ and Environmental Sciences, \\ University of KwaZulu-Natal, \\ Private Bag X01 Scottsville \\ 3209, South Africa \\ Tel: +27332605764 \\ Email: koetlisika@gmail.com
}

\begin{abstract}
Pyrolysis of latrine fecal waste could produce valuable products for minimizing environmental contamination with heavy metals. The objective of this study was to determine yields, characteristics and cadmium $(\mathrm{Cd})$ sorption of biochar from latrine fecal waste and sewage sludge, as affected by pyrolysis temperature. Slow pyrolysis at 350,550 and $650^{\circ} \mathrm{C}$, was used to produce the biochar. In addition to proximate and ultimate analysis, surface area, porosity and functional groups were analyzed. A batch sorption study was conducted to determine the cadmium sorption capacity of the biochar. Biochar from latrine waste had higher yield, ash content, surface area and pore volume and lower total and fixed carbon (C) and volatile matter than from sewage sludge. Yield, volatile matter, total $\mathrm{C}$, nitrogen $(\mathrm{N})$ and hydrogen $(\mathrm{H})$ decreased with pyrolysis temperature, while ash content, surface area and porosity increased. Surface functional groups of the biochar also varied with feedstock and pyrolysis temperature. The $\mathrm{Cd}$ sorption capacities were higher for biochar from latrine waste than from sewage sludge. The findings indicated that characteristics of biochar from latrine waste differ from that of sewage sludge origin and has greater potential as an adsorbent for removal of $\mathrm{Cd}$ from wastewater.
\end{abstract}

Keywords: Biochar, Cadmium, Latrine Fecal Waste, Sewage Sludge, Sorption

\section{Introduction}

The global generation of human fecal waste has increased over the past decades exacerbating the challenges of waste disposal (Seo et al., 2004; Al-Khatib et al., 2010). Cities in Southern Africa produce large quantities of human fecal wastes from wastewater treatment plants (sewage sludge) and pit latrines. Zuma et al. (2015) reported that $31.3 \%$ of households in South Africa depend on pit latrines and $12.5 \%$ use the Ventilated Improved Pit latrines (VIP), for their sanitation needs. The processes of filling of the pit with fecal matter (and other wastes), water transfer and biological transformations, over a 5-year cycle (before empting) (Zuma et al., 2015) influence the chemical composition of the latrine waste. Communities in the cities largely depend on the sewer systems, which treat wastewater and produce sewage sludge, through the anaerobic digestion and separation of the solid from the liquid (Snyman and Herselman, 2009). Exploitation of these organic wastes, particularly for production of resources like biochar, is essential for minimizing environmental pollution with heavy metals and other benefits (Gerente et al., 2007).
Differences in handling of latrine wastes and sewage sludge could result in variation in their characteristics (Tesfamariam, 2009) and those of the resultant biochar. Biochar from organic wastes has shown potential for removal of heavy metals from wastewater (Namgay et al., 2010; Major, 2011; Kim et al., 2013; Mohan et al., 2014; Coumar et al., 2016). Heavy metals, a group of elements with at least five times the density of water, are challenging environmental pollutants in places with elevated anthropogenic pressure (di Toppi and Gabbrielli, 1999). The metals enter the soil through pathways including agricultural, mining and other industrial activities (Coumar et al., 2016; Kabata-Pendias, 2000; Prasad, 1995). Production of biochar from latrine waste and sewage sludge could have potential uses in heavy metal removal from wastewater. Pyrolysis of these fecal wastes to biochar could recover carbon and nutrients (Hossain et al., 2011; Paz-Ferreiro et al., 2012; Mendez et al., 2012).

The effectiveness of biochar as a sorbent depends on its characteristics owing to the properties of the feedstock (Maraseni, 2010; Mitchell et al., 2013) and pyrolysis conditions (Trakal et al., 2014; Wan et al., 
2014; Kuppusamy et al., 2016; Bogusz et al., 2015). Analysis of the literature shows that lignified materials like wheat straw and water hyacinth produce biochar that has lower ash content and higher surface area than from sewage sludge (Xu et al., 2014; Tan et al., 2015). Differences in chemical composition of fecal wastes, as affected by diets (Mihelcic et al., 2011) and management, could influence characteristics of biochar produced from sewage sludge and latrine fecal wastes. Pyrolysis of these marginal organic materials to biochar could maximize their benefits (van Zwieten et al., 2010; Buss et al., 2016). The objective of this study was to determine effects of pyrolysis temperature on yield, characteristics and cadmium sorption capacities of biochar from latrine wastes relative to sewage sludge.

\section{Materials and Methods}

\section{Biochar Feedstock}

Latrine fecal wastes and domestic sewage sludge were used for production biocharin this study. The latrine waste was obtained by manually emptying of Ventilated and Improved Pit latrine (VIP) toilets in the eThekwini Municipality, South Africa. Due to non-separation of urine from feces, the waste appeared like pseudo-plastic fluid. The fecal wastes were pelletized by the latrine dehydration and pasteurization process at $200^{\circ} \mathrm{C}$ for eight minutes. The sewage sludge was collected from drying beds at Howick Wastewater Treatment Plant, $15 \mathrm{~km}$ north-west of Pietermaritzburg. The plant produces domestic sewage sludge with minimal industrial contamination. The latrine waste had lower $\mathrm{C}, \mathrm{N}, \mathrm{Na}$ and higher $\mathrm{Ca}, \mathrm{K}, \mathrm{C}: \mathrm{N}$ and $\mathrm{CEC}$ than sewage sludge (Table 1).

\section{Biochar Production}

The feed stocks were dried at $70^{\circ} \mathrm{C}$ for $24 \mathrm{~h}$ and milled to $<5 \mathrm{~mm}$ and slowly pyrolysed in $500 \mathrm{~mL}$ crucibles in a muffle furnace, equipped to reduce rapid oxidation and auto-ignition (Yuan et al., 2011; Enders et al., 2012). The furnace temperature was raised to set levels of 350,550 or

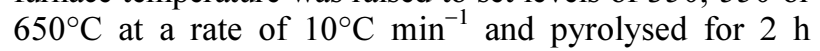
(Bamminger et al., 2014), in triplicate. The biochar was weighed to determine yield before characterization (Herath et al., 2013).

\section{Volatile Matter, Ash Content and Fixed C}

Volatile matter and ash content were determined using the proximate analyses following the reapproved American Society for Testing and Materials (ASTM) D1762 - 84 protocol (Wu et al., 2012). The pulverized samples were oven dried at $105^{\circ} \mathrm{C}$ for $2 \mathrm{~h}$ to determine moisture content. The biochar was subjected to $950^{\circ} \mathrm{C}$ furnace condition for six min and weight loss was taken as volatile matter, expressed as a percentage on a dry weight basis. Ash was determined after combustion at $750^{\circ} \mathrm{C}$ for six h. Fixed $\mathrm{C}$ was calculated by subtraction of volatile matter (\%) and ash (\%) from 100\% (Liu et al., 2014).
Table 1: Chemical properties (means \pm standard error) of sewage sludge and latrine waste pellets used for pyrolysis

\begin{tabular}{lll}
\hline Property & Latrine waste & Sewage sludge \\
\hline Total carbon (\%) & $9.29 \pm 0.17$ & $28.6 \pm 0.45$ \\
Total nitrogen (\%) & $0.86 \pm 0.01$ & $4.97 \pm 0.87$ \\
$\mathrm{C}: \mathrm{N}$ & 10.8 & 5.8 \\
$\mathrm{Ca}\left(\mathrm{cmol}+\mathrm{kg}^{-1}\right)$ & $32.2 \pm 0.93$ & $20.8 \pm 0.74$ \\
$\mathrm{Mg}\left(\mathrm{cmol}+\mathrm{kg}^{-1}\right)$ & $24.2 \pm 0.54$ & $25.1 \pm 1.11$ \\
$\mathrm{~K}\left(\mathrm{cmol}+\mathrm{kg}^{-1}\right)$ & $4.12 \pm 0.02$ & $2.68 \pm 0.08$ \\
$\mathrm{Na}\left(\mathrm{cmol}+\mathrm{kg}^{-1}\right)$ & $0.69 \pm 0.02$ & $14.7 \pm 0.59$ \\
$\mathrm{CEC}\left(\mathrm{cmol}+\mathrm{kg}^{-1}\right)$ & $17.8 \pm 0.37$ & $11.7 \pm 0.52$ \\
\hline
\end{tabular}

\section{Elemental Composition and Physico-Chemical Properties}

Total $C$ and $N$ were analyzed by dry combustion using LECO Trumac CNS analyzer (LECO Corporation, 2012). Furthermore, CHNS elemental analyzer was used to determine total $\mathrm{H}$.

The $\mathrm{pH}$ of biochar was determined in $\mathrm{H}_{2} \mathrm{O}$ and $\mathrm{KCl}$ at a solid: Solution ratio of 1:20 w/v ratio because of low bulk density of biochar (Cheng and Lehmann, 2009). The concentrations of exchangeable basic cations were extracted with $1 \mathrm{M} \mathrm{NH} \mathrm{NH}_{4} \mathrm{OAc}$ at $\mathrm{pH}$ 7. The air-dried biochar $(5.0 \mathrm{~g})$ were suspended in $100 \mathrm{~mL}^{-1}$ of $1 \mathrm{M}$ ammonium acetate $\left(\mathrm{NH}_{4} \mathrm{OAc}\right)$ and the mixtures were mechanically shaken at $180 \mathrm{rpm}$ for an hour and then filtered. The filtrate was analyzed for basic cations, using flame photometry $\left(\mathrm{K}^{+}\right.$and $\left.\mathrm{Na}^{+}\right)$and atomic absorption spectrometry $\left(\mathrm{Ca}^{2+}\right.$ and $\left.\mathrm{Mg}^{2+}\right)$. Cation Exchange Capacity (CEC) was determined as the concentration of $\mathrm{NH}_{4}^{+}$ retained after leaching with several portions of ethanol (Ross and Ketterings, 2011).

\section{Functional Groups, Surface Area and Porosity}

Chemical functional groups of the biochar were determined using the Fourier Transform Infrared (FTIR) spectroscopy (Coates, 2000). The FTIR transmission spectra were recorded on a PerkinElmer FT-IR at the wave numbers ranging from 550 to $4000 \mathrm{~cm}^{-1}$ (Wu et al., 2012). Chemical functional groups were then assigned to the wave numbers from the FTIR spectra. BrunauerEmmett-Teller (BET) surface area and pore volume and size were measured by nitrogen gas sorption analysis at $77 \mathrm{~K}$ bath temperature using Micromeritics Gemini BET Surface Area Analyser, Poretech, following the method used by Brewer et al. (2011).

\section{Batch Cd Sorption Studies}

The capacity of the biochar to sorb cadmium (Cd) was evaluated using a batch sorption study. The batch tests were replicated three times and blanks were run concurrently (Mohan et al., 2007). A stock solution 
containing $1000 \mathrm{mg} \mathrm{Cd} \mathrm{L}{ }^{-1}$ was prepared by dissolution of analytical grade of the metal in a $0.01 \mathrm{M} \mathrm{CaCl}_{2}$ as a background electrolyte. The solution was diluted to 5 , $10,15,20$ and $25 \mathrm{mg} \mathrm{Cd} \mathrm{L}^{-1}$ solutions with $0.01 \mathrm{M}$ $\mathrm{CaCl}_{2}$. The $0.01 \mathrm{M} \mathrm{CaCl}_{2}$ solution was used as the $0 \mathrm{mg}$ $\mathrm{Cd} \mathrm{L}^{-1}$ concentration. The Cd solutions $\left(25 \mathrm{~mL}^{-1}\right)$ were added to centrifuge tubes containing $2.5 \mathrm{~g}$ biochar samples. The suspensions were shaken at $180 \mathrm{rpm}$ at constant temperature $\left(25^{\circ} \mathrm{C}\right)$ for $24 \mathrm{~h}$ (Khodaverdiloo and Samadi, 2011) on a reciprocating shaker. The suspensions were centrifuged at $9440^{*} \mathrm{~g}$ for $10 \mathrm{~min}$ and the supernatants filtered through Whatman no. 42 filter paper (Khodaverdiloo and Samadi, 2011). A Fast Sequential Atomic Absorption Spectrometer (Model AA280FS) was used to measure metal (Cd) concentration in the supernatant. The $\mathrm{pH}$ of the supernatant was also measured. The amount of metal sorbed (S) was calculated as the difference between the amount added and the amount in the equilibrium solution, using Equation 1 (Desta, 2013):

$S=\frac{(\mathrm{Co}-\mathrm{Ce}) * V}{W}$

where, $S$ is the amount of $C d$ sorbed $\left(\mathrm{mg} \mathrm{kg}^{-1}\right), C_{0}$ and $C_{e}$ are the initial and equilibrium solution $C d$ concentrations $\left(\mathrm{mg} \mathrm{L}^{-1}\right), \mathrm{V}$ is the solution volume (L) and $\mathrm{W}$ is the adsorbent weight $(\mathrm{kg})$.

\section{Data Analysis}

All characteristics of biochar were subjected to a two-way analysis of variance (ANOVA) to show effects of pyrolysis temperature and feedstock type using Stata/IC 13.1 for Windows (1985-2013).
Adsorption data were fitted using a Langmuir isotherm model and sorption capacities were estimated (Kumar et al., 2011). Step-wise regression analysis was used to identify the best fit model to explain $\mathrm{Cd}$ sorption data by removing certain variables based on the t-statistics for estimated coefficients (Gray et al., 1999).

\section{Results and Discussion}

\section{Yield, Volatile Matter, Fixed Carbon and Ash Content of Fecal Biochar}

Biochar from latrine waste had higher yield than from sewage sludge and the yield decreased with increase in pyrolysis temperature (Table 2). Increasing pyrolysis temperature from 350 to $550^{\circ} \mathrm{C}$ decreased biochar yield by $6.7 \%(83.4 \%$ to $76.7 \%)$ for latrine waste and by $32.9 \%$ ( 74.3 to $41.4 \%)$ for sewage sludge. The least latrine waste biochar yield $\left(650^{\circ} \mathrm{C}\right)$ was similar to the highest for sewage sludge $\left(350^{\circ} \mathrm{C}\right)$. The loss of organic $\mathrm{C}$ associated with thermal degradation of ligno-cellulosic biomass and dehydration of organic compounds could explain the decrease in biochar yield with pyrolysis temperature (Liu et al., 2014). Thermal degradation of sewage sludge (higher total C) explains greater decline in yield and increase in total elemental composition than those from latrine waste with increasing pyrolysis temperatures. Sewage sludge biochar yield was lower than reported by Yuan et al. (2015), in the similar range as reported by Hossain et al. (2011) and higher than reported by Agrafioti et al. (2013). The composition of the sludges could explain the differences.

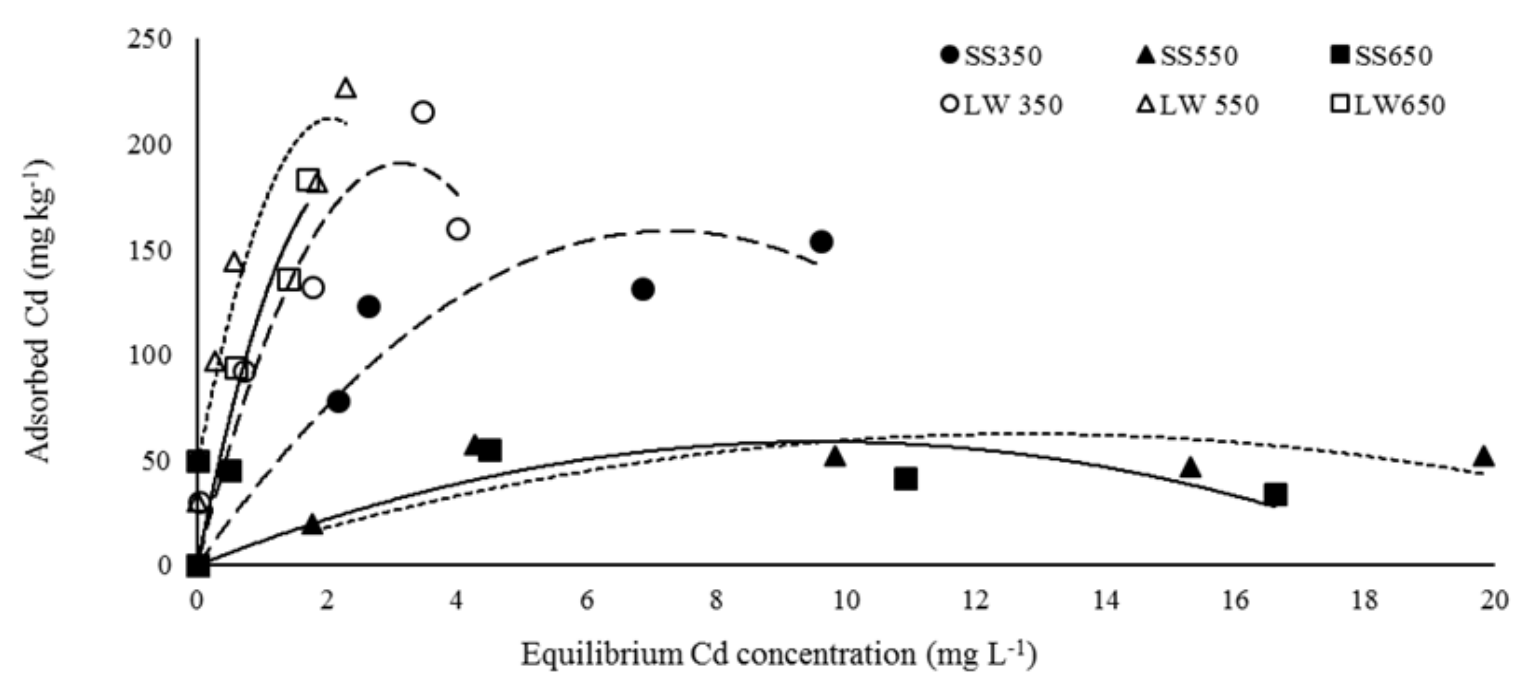

Fig. 1: Adsorption isotherms for six biochars; $S S=$ Sewage Sludge and $L W=$ latrine waste 
Volatile matter was higher in biochar from sewage sludge than latrine waste and the composition decreased with increase in pyrolysis temperature (Table 2). There was no significant difference in volatile matter on sewage sludge biochar at $550^{\circ} \mathrm{C}$ and latrine waste biochar at $350^{\circ} \mathrm{C}$. Higher volatiles are indicators of rich organic matter (Liu et al., 2014). The decrease in yield and volatile matter with increase in pyrolysis temperature was in agreement with Yuan et al., 2011; Enders et al., 2012; Wu et al., 2012; Mitchell et al., 2013; Hmid et al., 2014; Liu et al., 2014), for a variety of feed stocks. Trends of ash content were the exact opposite of those of volatile matter, with higher levels in biochar from latrine waste than from sewage sludge and the composition increased with increase in pyrolysis temperature (Table 2). Degradation of organic material (loss of volatile solids) during long storage times in the latrine (Zuma et al., 2015) could explain the higher ash content in latrine waste(85-93\%) than sewage sludge $(50-70 \%)$ biochar. The higher ash content in the two fecal wastes indicated lower organic $\mathrm{C}$ content, when compared with other feed stocks in the literature (Liu et al., 2014). Sewage sludge biochar had higher fixed $C$ than from latrine waste (Table 2). Increasing pyrolysis temperature from 350 and $550^{\circ} \mathrm{C}$ increased fixed $\mathrm{C}$ in sewage sludge biochar, while the fixed $\mathrm{C}$ decreased for latrine waste biochar. There were no differences in fixed $\mathrm{C}$ between 550 and $650^{\circ} \mathrm{C}$ for both feedstocks. The increase in fixed $\mathrm{C}$ with pyrolysis temperature was in agreement with Yuan et al., (2011; Enders et al., 2012; Wu et al., 2012; Mitchell et al., 2013; Hmid et al., 2014; Liu et al., 2014).

\section{Total Carbon, Nitrogen and Hydrogen Composition of Biochar}

Biochar from latrine waste had lower total $\mathrm{C}$ and $\mathrm{N}$ than sewage sludge biochar and the composition decreased with increase in pyrolysis temperature (Table 3). The trends were the opposite of that of ash, indicating that more ash relatively accumulated, as $\mathrm{C}$ and $\mathrm{N}$ are lost. The $\mathrm{C}: \mathrm{N}$ ratios were higher for latrine waste biochar than sewage sludge and generally increased with increase in pyrolysis temperature. The increase in pyrolysis temperature from 350 to $550^{\circ} \mathrm{C}$ resulted in decrease in $\mathrm{H}$ content in biochar from both feed stocks (Table 3). The $\mathrm{H}: \mathrm{C}$ ratios followed the same trend as that of $\mathrm{H}$ composition of the biochar. The decrease in $\mathrm{H}$ led to a decrease in $\mathrm{H}: \mathrm{C}$ molar ratio, an index of biochar aromaticity. Generally, the $\mathrm{H}: \mathrm{C}$ of the biochar ranging $0.02-0.1$ suggest condensed structure and more recalcitrant constituents (Kloss et al., 2012). Hmid et al. (2014) and van Zwieten et al. (2010) reported that biochar become more aromatic and carbonatious at high temperature due to a decline in $\mathrm{H} / \mathrm{C}$. However, the $\mathrm{H}: \mathrm{C}$ ratios in our study suggest that the biochar did not have significant aromaticity.

\section{pH, Electrical Conductivity, Exchangeable Bases and Cation Exchange Capacity}

Biochar $\mathrm{pH}$ increased with increase in pyrolysis temperature (Table 4). At $350^{\circ} \mathrm{C}$ latrine waste biochar had higher $\mathrm{pH}$ than sewage sludge, while at 550 and $650^{\circ} \mathrm{C}$ sewage sludge biochar had higher $\mathrm{pH}$. Generally, biochar $\mathrm{pH}$ (Table 4) increased with increase in pyrolysis temperature resulting in alkaline biochar (Wan et al., 2014). Electrical conductivity (EC) values of the biochar were low with no significant effects of pyrolysis temperature for latrine waste, while increasing temperature increased EC in sewage sludge biochar. Exchangeable $\mathrm{Ca}$ was higher in latrine waste biochar than from sewage sludge, with no effects of pyrolysis temperature. Exchangeable $K$ was lower in latrine waste than sewage sludge biochar. The composition decreased in sewage sludge biochar by raising pyrolysis temperature from 350 to $550^{\circ} \mathrm{C}$ and increased in latrine waste biochar from 550 to $650^{\circ} \mathrm{C}$. Exchangeable $\mathrm{Mg}$ was lower in latrine waste biochar than sewage sludge at $350^{\circ} \mathrm{C}$. Results of $\mathrm{Na}$ had no clear trend. Sewage sludge biochar at 550 and $650^{\circ} \mathrm{C}$ had lower CEC than the others. This was contrary to Mukherjee and Lal (2014), who reported that formation of phenolic functional groups might increase biochar CEC. The functional groups were only present at $650^{\circ} \mathrm{C}$ for latrine waste and at $350^{\circ} \mathrm{C}$ for sewage sludge (Table 5). The high ash content and low $C$ in fecal waste biochar could explain the difference. The higher CEC in latrine waste biochar could result in higher sorption of metals due to cation exchange (Inyang et al., 2016).

Table 2: Yield and proximate analyses results of biochars from human wastes

\begin{tabular}{llllll}
\hline Feedstock & Temperature $\left({ }^{\circ} \mathrm{C}\right)$ & Yield $(\%)$ & Volatiles $(\%)$ & Ash (\%) & Fixed C $(\%)$ \\
\hline Latrine waste & 350 & $83.55 \mathrm{a}$ & $10.27 \mathrm{~b}$ & $84.60 \mathrm{c}$ & $5.10 \mathrm{c}$ \\
& 550 & $76.71 \mathrm{~b}$ & $5.70 \mathrm{~d}$ & $90.23 \mathrm{~b}$ & $4.07 \mathrm{~d}$ \\
Sewage sludge & 650 & $75.00 \mathrm{c}$ & $3.10 \mathrm{e}$ & $92.97 \mathrm{a}$ & $3.97 \mathrm{~d}$ \\
& 350 & $74.31 \mathrm{c}$ & $36.13 \mathrm{a}$ & $49.57 \mathrm{f}$ & $14.33 \mathrm{~b}$ \\
& 550 & $41.42 \mathrm{~d}$ & $9.80 \mathrm{~b}$ & $66.77 \mathrm{e}$ & $23.37 \mathrm{a}$ \\
\hline
\end{tabular}

Means followed by the same letter in each column are not significantly different at $\mathrm{p}<0.05$ 
Table 3: Carbon, nitrogen and hydrogen composition of fecal biochars

\begin{tabular}{lllllll}
\hline Feedstock & Temperature $\left({ }^{\circ} \mathrm{C}\right)$ & $\mathrm{C}(\%)$ & $\mathrm{N}(\mathbf{\%})$ & $\mathrm{H}(\mathbf{\%})$ & $\mathrm{C} / \mathrm{N}$ & $\mathrm{H} / \mathrm{C}$ \\
\hline Latrine waste & 350 & $11.14 \mathrm{~d}$ & $1.04 \mathrm{c}$ & $1.01 \mathrm{~b}$ & $11: 01$ & 1.1 \\
& 550 & $8.73 \mathrm{ed}$ & $0.71 \mathrm{dc}$ & $0.36 \mathrm{c}$ & $12: 01$ & 0.3 \\
& 650 & $6.45 \mathrm{e}$ & $0.44 \mathrm{~d}$ & $0.35 \mathrm{c}$ & $15: 01$ & 0.4 \\
Sewage sludge & 350 & $31.19 \mathrm{a}$ & $5.45 \mathrm{a}$ & $2.64 \mathrm{a}$ & $6: 01$ & 1.0 \\
& 550 & $17.27 \mathrm{c}$ & $2.64 \mathrm{~b}$ & $1.02 \mathrm{~b}$ & $7: 01$ & 0.7 \\
& 650 & $20.85 \mathrm{~b}$ & $2.77 \mathrm{~b}$ & $0.71 \mathrm{cb}$ & $8: 01$ & 0.3 \\
\hline
\end{tabular}

Means followed by the same letter in each column are not significantly different at $\mathrm{p}<0.05$

Table 4: $\mathrm{pH}$, electrical conductivity, exchangeable bases and cation exchange capacity of the biochars

\begin{tabular}{|c|c|c|c|c|c|c|}
\hline \multirow[b]{2}{*}{ Elements } & \multicolumn{3}{|c|}{ Latrine waste } & \multicolumn{3}{|c|}{ Sewage sludge } \\
\hline & $350^{\circ} \mathrm{C}$ & $550^{\circ} \mathrm{C}$ & $650^{\circ} \mathrm{C}$ & $350^{\circ} \mathrm{C}$ & $550^{\circ} \mathrm{C}$ & $650^{\circ} \mathrm{C}$ \\
\hline $\mathrm{pH}\left(\mathrm{H}_{2} \mathrm{O}\right)$ & $6.94 b$ & $7.02 \mathrm{bc}$ & $7.14 \mathrm{~cd}$ & $5.89 \mathrm{e}$ & $7.27 \mathrm{~d}$ & $7.56 \mathrm{a}$ \\
\hline $\mathrm{pH}(\mathrm{KCl})$ & $6.93 \mathrm{~d}$ & $7.03 \mathrm{~d}$ & $7.17 \mathrm{c}$ & $6.05 \mathrm{e}$ & $7.47 \mathrm{~b}$ & $7.86 \mathrm{a}$ \\
\hline $\mathrm{EC}\left(\mu \mathrm{S} \mathrm{cm}^{-1}\right)$ & $36.86 b$ & $38.1 \mathrm{~b}$ & $41.6 \mathrm{ab}$ & $45.30 \mathrm{a}$ & $9.46 \mathrm{c}$ & $13.51 \mathrm{c}$ \\
\hline Exchangeable $\mathrm{Ca}\left(\mathrm{cmol}^{+} \mathrm{kg}^{-1}\right)$ & $9.74 b$ & $17.3 \mathrm{a}$ & $18.8 \mathrm{a}$ & $5.47 \mathrm{c}$ & $2.78 \mathrm{c}$ & $3.19 \mathrm{c}$ \\
\hline Exchangeable $\mathrm{Mg}\left(\mathrm{cmol}+\mathrm{kg}^{-1}\right)$ & $3.08 \mathrm{~b}$ & $4.06 \mathrm{ab}$ & $4.32 \mathrm{ab}$ & $4.88 \mathrm{a}$ & $3.44 \mathrm{ab}$ & $4.65 \mathrm{a}$ \\
\hline Exchangeable $\mathrm{K}\left(\mathrm{cmol}+\mathrm{kg}^{-1}\right)$ & $0.94 \mathrm{~d}$ & $1.04 \mathrm{~cd}$ & $0.58 \mathrm{e}$ & $3.30 \mathrm{a}$ & $1.25 \mathrm{cb}$ & $1.45 \mathrm{~b}$ \\
\hline Exchaangeable $\mathrm{Na}\left(\mathrm{cmol}+\mathrm{kg}^{-1}\right)$ & $0.90 \mathrm{c}$ & $1.40 \mathrm{~b}$ & $0.98 \mathrm{c}$ & $2.01 \mathrm{a}$ & $0.44 \mathrm{~d}$ & $1.02 \mathrm{c}$ \\
\hline Cation exchange capacity $\left(\mathrm{cmol}+\mathrm{kg}^{-1}\right)$ & $5.09 \mathrm{a}$ & $4.91 \mathrm{a}$ & $5.65 \mathrm{a}$ & $4.17 \mathrm{ab}$ & $2.31 \mathrm{c}$ & $2.40 \mathrm{bc}$ \\
\hline
\end{tabular}

Means followed by the same letter in each row are not significantly different at $\mathrm{p}<0.05$

Table 5: FTIR spectra of fecal biochars produced at different pyrolysis temperatures

\begin{tabular}{|c|c|c|c|c|c|c|c|}
\hline & & Biochars & & & & & \\
\hline Actual & & Latrine $\mathrm{w}$ & & & Sewage & dge & \\
\hline group frequency, & & ----- & & & & & \\
\hline wave number $\mathrm{cm}^{-1}$ & Functional group & $350^{\circ} \mathrm{C}$ & $550^{\circ} \mathrm{C}$ & $650^{\circ} \mathrm{C}$ & $350^{\circ} \mathrm{C}$ & $550^{\circ} \mathrm{C}$ & $650^{\circ} \mathrm{C}$ \\
\hline$* 3700-3500$ & N-H stretching of amide & 3694.07 & 3691.69 & & & & \\
\hline $3570-3200$ & O-H stretching of phenol & & & & 3338.16 & & \\
\hline$* 3000-2500$ & O-H stretching of carboxylic acid & 2642.94 & 2645.18 & 2646.13 & 2924.7 & 2644.1 & 2795.73 \\
\hline$* 1740-1690$ & $\mathrm{C}=\mathrm{O}$ stretching of aldehyde & 1714.77 & & & 1706.19 & & \\
\hline$* 1700-1500$ & $\mathrm{C}=\mathrm{C}$ bending of aromatic carbon & & & & 1559.47 & 1559.89 & 1560.98 \\
\hline $1650-1550$ & N-H secondary amine & 1559.16 & 1561.18 & 1561.22 & & & \\
\hline $1510-1450$ & $\mathrm{C}=\mathrm{C}-\mathrm{C}$ ring stretching of aromatic $\mathrm{C}$ & 1497.09 & 1497.09 & 1497.04 & & 1497.14 & 1496.98 \\
\hline $1490-1410$ & Carbonate ions & & & & 1446.79 & & \\
\hline $1410-1310$ & O-H bending of phenol (tertiary alcohol) & & & 1356.09 & & & \\
\hline $1240-1190$ & P-O-C stretching of aromatic phosphates & 1219.9 & 1219.86 & 1219.87 & 1219.85 & 1220 & 1220.03 \\
\hline $1100-1000$ & Phosphate ions & & & & & & 1068.05 \\
\hline $1050-990$ & Aliphatic phosphate & 1007.95 & 1009.67 & 1046.97 & 1047.04 & 1048.24 & \\
\hline $995-850$ & Aromatic phosphates & 913.16 & 914.83 & & & & \\
\hline $860-680$ & $\mathrm{C}-\mathrm{H}$ bending of aromatic $\mathrm{C}$ & 772.61 & 773.06 & 772.94 & 772.94 & 772.52 & 772.85 \\
\hline
\end{tabular}

Encyclopaedia of Analytical Chemistry (Coates, 2000)*Web Spectra (Merlic, 1997)

\section{Chemical Functional Groups of Fecal Biochar}

The chemical functional groups of the biochar are shown in Table 5. The $\mathrm{C}-\mathrm{H}$ bending of aromatic $\mathrm{C}$, aromatic P-O-C (1240-1190 $\left.\mathrm{cm}^{-1}\right)$ and carboxylic acid $\mathrm{O}-\mathrm{H}$ functional groups were present in all biochar irrespective of feedstock and pyrolysis temperature. The aldehyde $C=O$ functional group occurred only in biochar pyrolysed at $350^{\circ} \mathrm{C}$ irrespective of feedstock. All latrine waste biochar lacked the $C=C$ bending of aromatic $C$ and the aromatic carbon $C=O$ functional groups, which were present in sewage sludge biochar. All latrine waste biochar had amide N-H (except $650^{\circ} \mathrm{C}$ ) and secondary amine $\mathrm{N}-\mathrm{H}$ functional groups, which were absent in sewage sludge biochar. All biochar had the ring stretching of aromatic $\mathrm{C}(\mathrm{C}=\mathrm{C}$ C) except the sewage sludge biochar pyrolysed at $350^{\circ} \mathrm{C}$. The phenol O-H functional group $(3570-3200$ $\mathrm{cm}^{-1}$ ) and carbonate ion (1490-1410 $\left.\mathrm{cm}^{-1}\right)$ existed only on sewage sludge biochar pyrolysed at $350^{\circ} \mathrm{C}$. Increasing pyrolysis temperature could have resulted in formation of $\mathrm{C}=\mathrm{C}-\mathrm{C}$ groups from the phenol $\mathrm{O}-\mathrm{H}$ and carbonate ion, in sewage sludge biochar. Reduction in biochar yield with increase in pyrolysis temperature is associated with dehydration of organic compounds such as those with hydroxyl, phenolic and 
carboxylic acid groups (Liu et al., 2014; Novak et al., 2009). Aromatic phosphate functional group (995-850 $\mathrm{cm}^{-1}$ ) was only present in latrine waste biochar pyrolysed at 350 and $550^{\circ} \mathrm{C}$. On the other hand, the latrine waste biochar produced at $650^{\circ} \mathrm{C}$ was the only one with the phenol $\mathrm{O}-\mathrm{H}$ tertiary alcohol functional group $\left(1410-1310 \mathrm{~cm}^{-1}\right)$. The aliphatic phosphate functional group was present in all biochar except sewage sludge biochar pyrolysed at $650^{\circ} \mathrm{C}$; the only one with phosphate ions, suggesting that the functional group mineralized at high temperature. On the other hand, $\mathrm{C}=$ $\mathrm{O}$ stretching of aldehyde on latrine waste biochar diminished with increase in pyrolysis temperature.

\section{Surface Area, Pore Volume and Pore Size}

Latrine waste biochar had higher surface area and pore volume than those from sewage sludge (Table 6) The higher surface area and pore volume of latrine waste biochar suggested that these biochar could encourage more physical metal sorption than those from sewage sludge (Inyang et al., 2016). Surface area and pore volume increased, whereas pore size decreased, with increase in pyrolysis temperature. There was greater change in surface area, pore volume and pore size as a result of increasing pyrolysis temperature from 350 to $550^{\circ} \mathrm{C}$ than from 550 to $650^{\circ} \mathrm{C}$. As volatile components escape they leave voids, which leads to improvement in the porosity and exposing greater surface area of the carbonized biomass (Ahmad et al., 2012; Downie et al., 2011). The rapid decline in volatile compounds and associated increase in specific surface area, in our study, supports this view. Lower volatile compounds and high ash content in latrine waste biochar, because of $\mathrm{C}$ losses during storage, explains the higher porosity and surface area even at $350^{\circ} \mathrm{C}$.

Latrine waste biochar had higher surface area than reported by Agrafioti et al. (2013) for sewage sludge. While latrine waste biochar had similar surface area than those reported by Yuan et al. (2015), sewage sludge biochar were lower. However, the pore volume in our study was lower, indicating that our biochar were less porous. The increase in surface area and micro-porosity due to pyrolysis could enhance metal retention when used as adsorbents (Masto et al., 2013). The higher sorption capacity of latrine waste biochar than sewage sludge appeared related to the surface area. However, the increase in surface area in latrine waste biochar was not correlated with $\mathrm{Cd}$ sorption, in agreement with Trakal et al. (2014), who reported that removal of $\mathrm{Cd}$ was least influenced by biochar morphology and specific surface area.

\section{Cadmium Sorption on Fecal Biochar}

The Cd sorption data fitted he Langmuir isotherms (Fig. 1). The different $\mathrm{Cd}$ sorption capacities and the constants relating to bonding energy (b) of different biochar are in Table 7. The fit of Langmuir model suggests that $\mathrm{Cd}$ sorption on the biochar is a monolayer process (Bogusz et al., 2015; Trakal et al., 2014). Greater sorption occurred on latrine waste biochar than on sewage sludge biochar, which could be explained by the higher ash, CEC and surface area. Cadmium sorption on both latrine waste and sewage sludge decreased with increase in pyrolysis temperature, except that sorption on latrine waste biochar at $550^{\circ} \mathrm{C}$ was higher than that on $350^{\circ} \mathrm{C}$. The $\mathrm{R}^{2}$ were $>0.900$. The constants relating to bonding energy were higher on latrine waste $\left(\geq 40 \mathrm{~L} \mathrm{~kg}^{-1}\right)$ than sewage sludge $\left(<1.2 \mathrm{~L} \mathrm{~kg}^{-1}\right)$.

\section{Relationships of Biochar Characteristics and Cadmium Sorption}

Step-wise regression (Table 8) analysis showed that equation $\mathrm{Cd}$ sorption capacity could be explained $(\mathrm{p}<0.05)$ by a combination of ash and total $\mathrm{P}(\mathbf{S m a x}=$ 1.960 ash $\mathbf{- 9 . 0 2 8}$ total $P+\mathbf{2 5 5 . 6 9 6 )}$ and of ash and $\mathrm{pH}($ Smax $=$ 4.177 Ash - 97.429 pH + 525.562). Although there appears to be relationships between Cd sorption capacity and ash, surface area and CEC, only ash, total $\mathrm{P}$ and $\mathrm{pH}$ had significant effects. The CEC and surface areas could have been too low and could have been masked by effects of ash and total $\mathrm{P}$ and $\mathrm{pH}$. Omission of ash led to insignificant effect with low correlation coefficient and $\mathrm{p}>0.05$, which indicated that ash is the most important component in the sorption of $\mathrm{Cd}$ on these fecal biochar. The positive correlation of $\mathrm{Cd}$ sorption with ash content was in agreement with $\mathrm{Xu}$ et al. (2014) and suggested that minerals in the ash dominated the sorption process. Calcium hydroxyapatite and calcium carbonates in bone biochar have been shown to promote ion exchange reactions of heavy metals (Inyang et al., 2016). The higher $\mathrm{Ca}$ than total $\mathrm{P}$ in latrine waste biochar indicate that $\mathrm{Ca}$ in the ash occurred mainly as carbonates, providing sorption sites for $\mathrm{Cd}$ (Xu et al., 2014). Phosphorus could have precipitated with $\mathrm{Cd}$ at $\mathrm{pH}$ 6.0-7.0, resulting in higher sorption than at higher $\mathrm{pH}$. At higher $\mathrm{pH}$, precipitates with $\mathrm{Ca}$ and $\mathrm{Mg}$ are formed and $\mathrm{P}$ becomes less available to precipitate with $\mathrm{Cd}$, lowering sorption. This effect would have been more important for sewage sludge, which had higher $\mathrm{P}$ and lower $\mathrm{Cd}$ sorption at higher $\mathrm{pH}$ (7.5-7.9). The decline in exchangeable $\mathrm{Ca}$ with pyrolysis temperature for sewage sludge supported this view. However, this effect could have been lower for latrine waste biochar, which had lower P. In these biochar types, $\mathrm{P}$ content and $\mathrm{pH}$ did not change because the material was low in volatile solids. 
Table 6: Surface area, pore volume and size of the resultant biochars

\begin{tabular}{llccr}
\hline Feedstock & Pyrolysis temperature $\left({ }^{\circ} \mathrm{C}\right)$ & Surface Area $\left(\mathrm{m}^{2} \mathrm{~g}^{-1}\right)$ & Pore Volume $\left(\mathrm{cm}^{3} \mathrm{~g}^{-1}\right)$ & Pore Size $(\AA)$ \\
\hline Latrine waste & 350 & 7.5 & 0.0350 & 183.1 \\
& 550 & 23.7 & 0.0530 & 91.0 \\
Sewage sludge & 650 & 25.7 & 0.0520 & 81.2 \\
& 350 & $0.3^{*}$ & 0.0008 & 112.9 \\
& 550 & 1.6 & 0.0051 & 129.8 \\
\end{tabular}

*Volatiles came off the sample during analysis resulting in negative gas adsorption values (not suitable for BET analysis)

Table 7: Effect of pyrolysis temperature on Cd sorption maximum

\begin{tabular}{lllll}
\hline Feedstock & Pyrolysis temperature $\left({ }^{\circ} \mathrm{C}\right)$ & $\mathrm{Smax}\left(\mathrm{mg} \mathrm{kg}^{-1} \mathrm{Cd}\right)$ & $\mathrm{b}\left(\mathrm{L} \mathrm{kg}^{-1} \mathrm{Cd}\right)$ & $\mathrm{R}^{2}$ \\
\hline Latrine waste & 350 & 200.0 & 50.00 & 0.98 \\
& 550 & 250.0 & 40.00 & 0.96 \\
Sewage sludge & 650 & 167.0 & 60.00 & 0.90 \\
& 350 & 143.0 & 0.78 & 0.98 \\
& 550 & 55.6 & -1.56 & 0.97 \\
\hline
\end{tabular}

Table 8: Multiple and step-wise regression analysis to identify the most influential parameter(s) on Cd Smax; Cd as a model element

\begin{tabular}{|c|c|c|c|c|}
\hline $\begin{array}{l}\text { Step-wise regression } \\
\text { Smax }\left(\mathrm{mg} \mathrm{kg}^{-1}\right)\end{array}$ & $\begin{array}{l}\text { Cd regression output } \\
\text { coefficients }\end{array}$ & Standard error & $P>|t|$ & $\mathrm{P}$ as a whole \\
\hline Ash \% & 2.416 & 1.509 & 0.251 & 0.161 \\
\hline Total P $\left(\mathrm{g} \mathrm{kg}^{-1}\right)$ & -7.607 & 4.042 & 0.201 & \\
\hline Total $\mathrm{Al}\left(\mathrm{g} \mathrm{kg}^{-1}\right)$ & -1.591 & 3.207 & 0.669 & \\
\hline Constant $(a)$ & 211.184 & 163.183 & 0.325 & \\
\hline \multicolumn{5}{|l|}{$\operatorname{Smax}\left(\mathrm{mg} \mathrm{kg}^{-1}\right)$} \\
\hline Ash \% & 1.96 & 1.037 & 0.155 & 0.044 \\
\hline Total P $\left(\mathrm{g} \mathrm{kg}^{-1}\right)$ & -9.028 & 2.464 & 0.035 & \\
\hline Constant $(a)$ & 255.696 & 117.931 & 0.119 & \\
\hline \multicolumn{5}{|l|}{$\operatorname{Smax}\left(\mathrm{mg} \mathrm{kg}^{-1}\right)$} \\
\hline Ash \% & 3.995 & 1.705 & 0.101 & 0.169 \\
\hline Total $\mathrm{Al}\left(\mathrm{g} \mathrm{kg}^{-1}\right)$ & -5.872 & 3.071 & 0.152 & \\
\hline Constant $(a)$ & -44.703 & 122.612 & 0.740 & \\
\hline \multicolumn{5}{|l|}{$\operatorname{Smax}\left(\mathrm{mg} \mathrm{kg}^{-1}\right)$} \\
\hline Total $\mathrm{P}\left(\mathrm{g} \mathrm{kg}^{-1}\right)$ & -11.204 & 4.142 & 0.073 & 0.127 \\
\hline Total Al $\left(\mathrm{g} \mathrm{kg}^{-1}\right)$ & 1.531 & 3.139 & 0.659 & \\
\hline Constant $(a)$ & 436.51 & 101.765 & 0.023 & \\
\hline \multicolumn{5}{|l|}{$\operatorname{Smax}\left(\mathrm{mg} \mathrm{kg}^{-1}\right)$} \\
\hline Ash \% & 4.177 & 0.888 & 0.018 & 0.025 \\
\hline $\mathrm{pH}_{\mathrm{KCl}}$ & -97.429 & 21.256 & 0.019 & \\
\hline Constant $(a)$ & 525.562 & 144.834 & 0.036 & \\
\hline
\end{tabular}

\section{Conclusion}

Biochar from latrine fecal waste have higher yields, ash, $\mathrm{Ca}, \mathrm{Fe}$, surface area, porosity and cadmium sorption capacity and lower fixed $\mathrm{C}$, than those from sewage sludge. Increasing pyrolysis temperature increases surface area and porosity and decreases biochar yield, volatile matter and $\mathrm{Cd}$ sorption capacity. Surface functional groups on biochar differ between the fecal wastes and among pyrolysis temperatures. Ash, $\mathrm{pH}$ and $\mathrm{P}$ content are the most important parameters governing $\mathrm{Cd}$ sorption on fecal biochar. Further research is required on sorption of other heavy metals on these fecal biochar when compared with wood derived biochar.

\section{Acknowledgements}

The Pollution Research Group of the University of KwaZulu-Natal assisted with biochar production. The WK Kellogg Foundation Southern Africa Scholarships funded the study but was not involved in the design, data collection, analysis and writing of the manuscript.

\section{Author's Contributions}

Koetlisi Andreas Koetlisi: Designed all experiments, did data-collection and analysis and wrote the first draft of the manuscript.

Pardon Muchaonyerwa: was the supervisor of the lead author's $\mathrm{PhD}$ for which this paper is a part. He participated 
in the designs and carrying out of all experiments, datacollection and analysis, and writing of the manuscript.

\section{Ethics}

This research article is original and has not been published elsewhere and or/does not contain any published material in its content. The authors have read and approved the manuscript and no ethical issues involved.

\section{References}

Agrafioti, E., G. Bouras, D. Kalderis and E. Diamadopoulos, 2013. Biochar production by sewage sludge pyrolysis. J. Anal. Applied Pyrol., 101: 72-78.

Ahmad, M., S.S. Lee, X. Dou, D. Mohan and J. Sung et al., 2012. Effects of pyrolysis temperature on soybean stover and peanut shell-derived biochar properties and TCE adsorption in water. Bioresource Technol., 118: 536-544.

Al-Khatib, A.I., M. Monou, A.S.F. Abu Zahra, H.Q. Shaheen and D. Kassinos, 2010. Solid waste characterization, quantification and management practices in developing countries. A case study: Nablus district - Palestine. J. Environ. Manage., 91: 1131-1138.

Bamminger, C., B. Marschner and E. Juschke, 2014. An incubation study on the stability and biological effects and pyrogenic and hydrothermal biochar in two soils. Eur. J. Soil Sci., 65: 72-82.

Bogusz, A., P. Oleszczuk and R. Dobrowolski, 2015. Application of laboratory prepared and commercially available biochars to adsorption of cadmium, copper and zinc ions from water. Bioresource Technol., 196: 540-549.

Brewer, C.E., R. Unger, K. Schmidt-Rohr and C. Brown, 2011. Criteria to select biochars for field studies based on biochar chemical properties. Bioenerg. Res., 4: 312-323.

Buss, W., M.C. Graham, J.G. Shepherd and O. Mašek, 2016. Suitability of marginal biomass-derived biochars for soil amendment. Sci. Total Environ., 547: 314-322. DOI: 10.1016/j.scitotenv.2015.11.148

Cheng, C.H. and J. Lehmann, 2009. Aging of black carbon along a temperature gradient. Chemosphere, 75: 1021-1027.

Coates, J., 2000. Interpretation of Infrared Spectra, a Practical Approach. In: Encyclopedia of Analytical Chemistry, Meyers, R.A. (Ed.), John Wiley and Sons Ltd, Chichester, pp: 10815-10837.

Coumar, M.V., R.S. Parihar, A.K. Dwivedi, J.K. Saha and S. Rajendiran et al., 2016. Impact of pigeon pea biochar on cadmium mobility in soil and transfer rate to leafy vegetable spinach. Environ. Monitoring Assessment, 188: 31-31. DOI: $10.1007 / \mathrm{s} 10661-015-5028-\mathrm{y}$
Desta, M.B., 2013. Batch sorption experiments: Langmuir and Freundlich isotherm studies for the adsorption of textile metal ions onto Teff straw (Eragrostistef) agricultural waste: Hindawi publishing corporation. J. Thermodynamics.

di Toppi, L.S. and R. Gabbrielli, 1999. Response to cadmium in higher plants. Environ. Experimental Botany, 41: 105-130.

Downie, A.E., L. Van Zwieten, R.J. Smernik, S. Morris and P.R. Munroe, 2011. Terra preta Australis: Reassessing the carbon storage capacity of temperate soils. Agr. Ecosyst. Environ., 140: 137-147.

Enders, A., K. Hanley, T. Whitman, S. Joseph and J. Lehmann, 2012. Characterization of biochars to evaluate recalcitrance and agronomic performance. Bioresource Technol., 114: 644-653.

Gerente, C., V.K.C. Lee, P., Le Cloirec and G. McKay, 2007. Application of Chitosan for the removal of metals from wastewaters by adsorption mechanisms and models review. Critical Rev. Environ. Sci. Technol., 37: 41-127.

Gray, C.W., R.G. McLaren, A.H.C. Roberts and L.M. Condron, 1999. Solubility, sorption and desorption of native and added cadmium in relation to properties of soils in New Zealand. Eur. J. Soil Sci., 50: 127-137. DOI: 10.1046/j.1365-2389.1999.00221.x

Herath, H.M.S.K., M. Camps-Arbestain and M. Hedley, 2013. Effect of biochar on soil physical properties in two contrasting soils: An Alfisol and an Andisol. Geoderma, 209-210: 188-197.

Hmid, A., D. Mondelli, S. Fiore, F.P. Fanizzi, Z.A. Chami and S. Dumontet, 2014. Production and characterization of biochars from three-phase olive mill waste through slow pyrolysis. Biomass Bioenerg., 71: 330-339.

Hossain, M.K., V. Strezov, K.Y. Chan, A. Ziolkowski and P.F. Nelson, 2011. Influence of pyrolysis temperature on production and nutrient properties of wastewater sludge biochar. J. Environ. Manage., 92: 223-228.

Inyang, M.I., B. Gao, Y. Yao, Y. Xue and A.R. Zimmerman et al., 2016. A review of biochar as a low cost adsorbent for aqueous heavy metal removal. Critical Rev. Environ. Sci. Technol., 46: 406-433.

Kabata-Pendias, A., 2000. Trace Elements in Soils and Plants. 1st Edn., CRC Press, London.

Kloss, S., F. Zehetner, A. Dellantonio, R. Hamid and F. Ottner et al., 2012. Characterization of slow pyrolysis biochars: Effects of feedstocks and pyrolysis temperature on biochar properties. J. Environ. Qual., 41: 990-1000.

Khodaverdiloo, H. and A. Samadi, 2011. Batch equilibrium study on sorption, desorption and immobilization of cadmium in some semi-arid zone soils as affected by soil properties. Soil Res., 49: 444-454. 
Kim, W.K., T. Shim, Y.S. Kim, S. Hyun and C. Ryu et al., 2013. Characterization of cadmium removal from aqueous solution by biochar produced from a giant Miscanthus at different pyrolytic temperatures. Bioresour. Technol., 138: 266-270.

Kumar, S., V.A. Loganathan, B. Ram R.B. Gupta and M.O. Barnett, 2011. An Assessment of U(VI) removal from groundwater using biochar produced from hydrothermal carbonization. J. Environ. Manage., 92: 2504-2512.

Kuppusamy, S., P. Thavamani, M. Megharaj, K. Venkateswarlu and R. Naidu, 2016. Agronomic and remedial benefits and risks of applying biochar to soil: Current knowledge and future research directions. Environ. Int., 87: 1-12.

Liu, X., Z. Li, Y. Zhang, R. Feng and I.B. Mahmood, 2014. Characterization of human manure-derived biochar and energy-balance analysis of slow pyrolysis process. Waste Manage., 34: 1619-1626.

Major, J., 2011. Biochar for soil remediation and land reclamation. Int. Biochar Initiative Res. Summaries.

Maraseni, T.N., 2010. Biochar: Maximising the benefits. Int. J. Environ. Stud., 67: 319-327.

Masto, R.E., M.A. Ansari, J. George, V.A. Selvi and L.C. Ram, 2013. Co-application of biochar and lignite fly ash on soil nutrients and biological parameters at different crop growth stages of Zea mays. Ecol. Eng., 58: 314-322.

Merlic, C.A., 1997. WebSpetra: Problems in NMR and IR spectroscopy. University of Califonia. [n.p.].

Mendez, A., A. Gomez, J. Paz-Ferreiro and G. Gasco, 2012. Effects of sewage sludge biochar on plant metal availability after application to a Mediterranean soil. Chemosphere, 89: 1354-1359.

Mihelcic, J.R., L.M. Fry and R. Shaw, 2011. Global potential of phosphorus recovery from human urine and faeces. Chemosphere, 84: 832-839.

Mitchell, P., T.S.L. Dalley and R.J. Helleur, 2013. Preliminary laboratory production and characterization of biochars from lignocellulosic municipal waste. J. Anal. Applied Pyrol., 99: 71-78.

Mohan, D., C.U. Pittman, M. Bricka, F. Smith and B. Yancey et al., 2007. Sorption of arsenic, cadmium and lead by chars produced from fast pyrolysis of wood and bark during bio-oil production. J. Colloid Interface Sci., 310: 57-73.

Mohan, D., H. Kumar, A. Sarswat, M. Alexandre-Franco and C.U. Pittman, 2014. Cadmium and lead remediation using magnetic oak wood and oak bark fast pyrolysis bio-chars. Chem. Eng. J., 236: 513-528.

Mukherjee, A. and R. Lal, 2014. The biochar dilemma. Soil Res., 52: 217-230.

Namgay, T., B. Singh and B.P. Singh, 2010. Influence of biochar application to soil on the availability of As, $\mathrm{Cd}, \mathrm{Cu}, \mathrm{Pb}$ and $\mathrm{Zn}$ to maize (Zea mays L.). Australian J. Soil Res., 48: 638-647.
Novak, J.M., I. Lima, B. Xing, J.W. Gaskin and C. Steiner et al., 2009. Characterization of designer biochar produced at different temperatures and their effects on a loamy sand. Ann. Environ. Sci.

Paz-Ferreiro, J., G. Gasco, B. Gutierrez and A. Mendez, 2012. Soil biochemical activities and the geometric mean of enzyme activities after application of sewage sludge and sewage sludge biochar to soil. Biol. Fert. Soils, 48: 511-517. DOI: 10.1007/s00374-011-0644-3

Prasad, M.N.V., 1995. Cadmium toxicity and tolerance in vascular plants. Environ. Exp. Bot., 35: 525-545.

Ross, D.S. and Q. Ketterings, 2011. Recommended methods for determining soil cation exchange capacity. In: recommended soil testing procedures for the north-eastern United States. Cooperative Bull., 493: 75-86.

Seo, S., T. Aramaki, Y. Hwang and K. Hanaki, 2004. Environmental impact of solid waste treatment methods in Korea. J. Environ. Eng., 130: 81-89.

Snyman, H.G. and J.E. Herselman, 2009. Guidelines for the Utilization and Disposal of Wastewater Sludge. In: Wastewater Sludge: Volume 3 of 5: Requirements for the On-site and Off-site Disposal of Sewage Sludge, Ekama, G.A. (Ed.), WRC Project No. K5/1622-3, Pretoria.

Stata/IC 13.1 for Windows, 1985-2013. Statistics/data analysis. StataCorp LP.

Tan, X., Y. Liu, G. Zeng, X. Wang and X. Hu et al., 2015. Application of biochar for the removal of pollutants from aqueous solutions. Chemosphere, 125: 70-85 DOI: 10.1016/j.chemosphere.2014.12.058

Tesfamariam, E.H., 2009. Sustainable use of sewage sludge as a source of nitrogen and phosphorus in cropping systems. PhD Thesis University of Pretoria, South Africa.

Trakal, L., D. Bingol, M. Pohorely, M. Hruska and M. Komarek, 2014. Geochemical and spectroscopic investigations of $\mathrm{Cd}$ and $\mathrm{Pb}$ sorption mechanisms on contrasting biochars: Engineering implications. Bioresour. Technol., 171: 442-451.

van Zwieten, L., S. Kimber, S. Morris, K.Y. Chan and A. Downie et al., 2010. Effects of biochar from slow pyrolysis of paper-mill waste on agronomic performance and soil fertility. Plant Soil, 327: 235-246.

Wan, Q., J. Yuan, R. Xu and X. Li, 2014. Pyrolysis temperature influences ameliorating effects of biochars on acid soil. Environ. Sci. Pollut. Res., 21: 2486-2495.

Wu, W., M. Yang, Q. Feng, K. McGrouther and H. Wang et al., 2012. Chemical characterization of rice straw-derived biochar for soil amendment. Biomass Bioenerg., 47: 268-276. 
Xu, D., Y. Zhao, K. Sun, B. Gao and Z. Wang et al., 2014. Cadmium adsorption on plant- and manurederived biochar and biochar-amended sandy soils: Impact of bulk and surface properties. Chemosphere, 111:320-326.

Yuan, J.H., R.K. Xu and H. Zhang, 2011. The forms of alkalis in the biochar produced from crop residues at different temperatures. Bioresource Technol., 102: 3488-3497.
Yuan, H., T. Lu, H. Huang, D. Zhao and N. Kobayashi et al., 2015. Influence of pyrolysis temperature on physical and chemical properties of biochar made from sewage sludge. J. Anal. Applied Pyrol., 112: 284-289.

Zuma, L., K. Velkushanova and C. Buckley, 2015. Chemical and thermal properties of VIP latrine sludge. Water SA. 